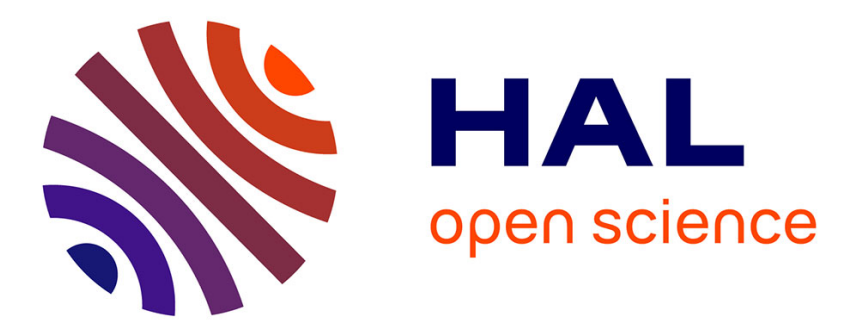

\title{
Recognizing overlapped particles during a crystallization process from in situ video images for measuring their size distributions
}

Ola Suleiman Ahmad, Johan Debayle, Nesrine Gherras, Benoît Presles, Gilles Févotte, Jean-Charles Pinoli

\section{To cite this version:}

Ola Suleiman Ahmad, Johan Debayle, Nesrine Gherras, Benoît Presles, Gilles Févotte, et al.. Recognizing overlapped particles during a crystallization process from in situ video images for measuring their size distributions. Journal of Electronic Imaging, 2012, 21 (2), pp.0211115. 10.1117/1.JEI.21.2.021115 . hal-00733252

\section{HAL Id: hal-00733252 \\ https://hal.science/hal-00733252}

Submitted on 18 Sep 2012

HAL is a multi-disciplinary open access archive for the deposit and dissemination of scientific research documents, whether they are published or not. The documents may come from teaching and research institutions in France or abroad, or from public or private research centers.
L'archive ouverte pluridisciplinaire HAL, est destinée au dépôt et à la diffusion de documents scientifiques de niveau recherche, publiés ou non, émanant des établissements d'enseignement et de recherche français ou étrangers, des laboratoires publics ou privés. 


\title{
Recognizing overlapped particles during a crystallization process from in situ video images for measuring their size distributions
}

\author{
Ola Suleiman $\operatorname{Ahmad}^{a}$, Johan Debayle ${ }^{a}$, Nesrine Gherras ${ }^{a}$, Benoît Presles ${ }^{a}$, Gilles Févotte $^{a, b}$ \\ and Jean-Charles Pinoli ${ }^{a}$ \\ ${ }^{a}$ École Nationale Supérieure des Mines de Saint-Etienne, LPMG, UMR CNRS 5148, \\ 158 cours Fauriel, 42023 Saint-Etienne cedex 2, France. \\ ${ }^{b}$ Université Lyon 1, Campus de la Doua, \\ 43 Boulevard du 11 Nov. 1918, 69622 Villeurbanne Cedex, France.
}

\begin{abstract}
This paper presents a method to recognize polygonal-shaped particles (i.e. rectangles, regular/irregular prisms) among agglomerated crystals from in situ images during a crystallization process. The aim is to measure the particle size distributions (PSD), which are key measurements needed for the purification operations and the quality control of chemical products or drugs. The method is first based on detecting the geometric features of the particles identified by their salient corners. A clustering technique is then applied by grouping three correspondent salient corners belonging to the same polygon. The efficiency of the proposed method is tested on particles of Ammonium Oxalate during batch crystallization in pure water. Particle size distributions are calculated, and a quantitative comparison between automatic and manual sizing is performed.
\end{abstract}

Keywords: Crystallization, Salient Corner Detection, Grouping Method, Shape Recognition, Particle Size Distributions.

\section{INTRODUCTION}

Crystallization is a chemical engineering process which is used in time-continuous mode in order to produce solid products such as sodium, ammonium sulfate and potassium chlorides, and in batch mode to fabricate fine chemicals and drugs. It consists of two major events. The first event is the nucleation, where the solute molecules distributed in the solvent aggregate and increase the concentration of the solute, then stabilize under certain conditions to form the nuclei. The second event is the crystal growth, where the nuclei growths and reaches a critical size to finally form one or different crystal structures called polymorphisms. Controlling the particle shape and size distributions (PSD) is very important to precisely evaluate the quality of the final drugs and chemical products, and to the downstream processes. ${ }^{1}$

The main challenge to achieve a successful and robust characterization of the PSD by image analysis is the segmentation process, which aims to separate the particles from the background and ones from each others. It becomes a critical problem in crystallization because of several reasons, such as: the perspective projection of the $3 \mathrm{D}$ crystal shape onto the image plane, the blurred appearance of unfocused particles, the heterogeneity and the anisotropy of the solute, the degree of agglomeration or overlap, and the random variation in size of the observed particles. Many methods have been proposed to detect the crystals for monitoring the particle size distribution. An algorithm ${ }^{2}$ based on line segment detection ${ }^{3}$ was proposed to detect rectangular crystals by assuming that the rectangular object can be constructed from two or more line segments. In their preceding work, ${ }^{4}$ the algorithm is modified to be used to detect prismatic crystals basing on 3D-model fitting. In both applications, the results was satisfied in detecting accurately the overlapped particles from images but in low solids concentrations, where the particles are small enough with no high degree of overlap. However, the performance of the algorithm declines

Further author information:

Ola Suleiman Ahmad: E-mail: ahmad@emse.fr 


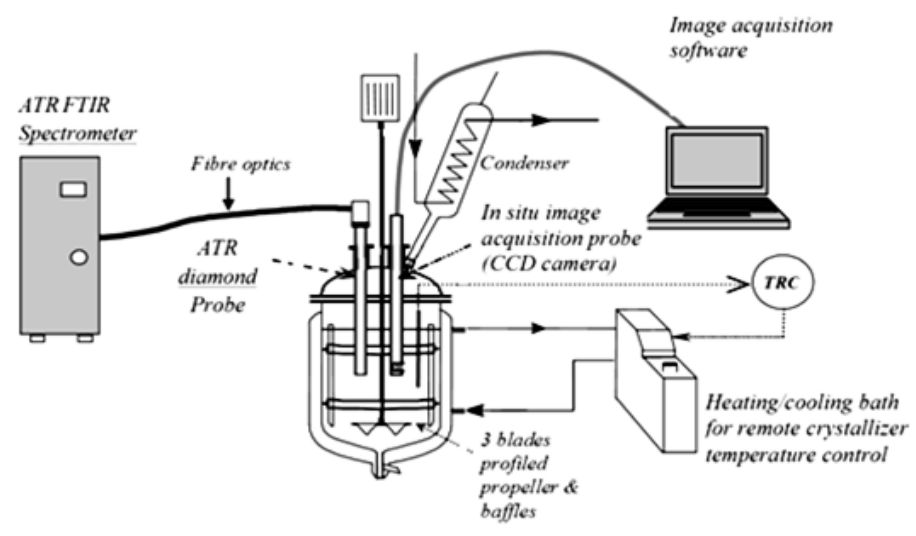

(a)

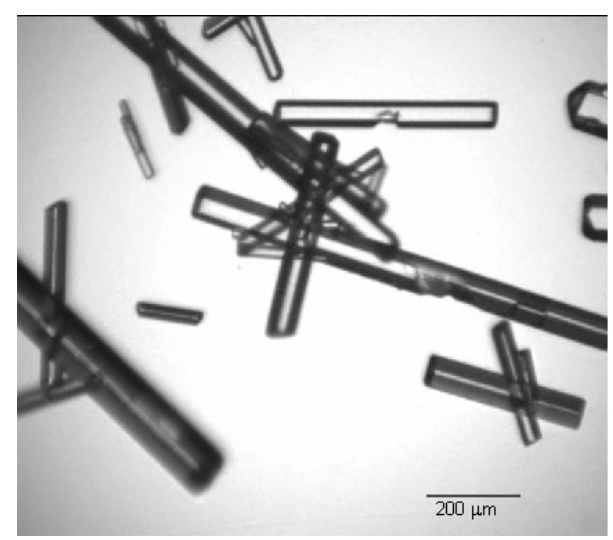

(b)

Figure 1. (a) Experimental setup of batch crystallization process. (b) A gray level image of Ammonium Oxalate crystals in pure water.

in high solids concentrations and with the existence of unfocused objects. A multi-scale segmentation method ${ }^{5}$ was proposed and found to be effective for extracting crystals from unclear background of varied illumination, but the overlapped particles are detected as one object which is unwanted for the present paper setting. In the recent work ${ }^{6}$ related to the last one, ${ }^{5}$ the concave points are extracted from the detected particles ${ }^{5}$ which are defined as markers for a marker-controlled watershed algorithm ${ }^{7}$ in order to separate the overlapped crystals. The method showed efficiency in separating the attached particles even at high solids concentrations, but it was not sufficient to detect the overlapped crystals of polygonal shapes. A restoration $\operatorname{method}^{8}$ was proposed for detecting unfocused crystals from a segmented image ${ }^{7}$ for achieving an accurate measurement of the particle size distribution. However, the method detects the overlapped crystals as individual ones.

The goal of this paper is to outline an applied efficient method, based on image analysis, ${ }^{9,10}$ that will be able to separate the overlapped particles of rectangular and regular/irregular shapes during the batch crystallization process at different solids concentrations. This paper is organized as follows. The experimental setup of the crystallization process is presented in section 2. The image segmentation method of overlapped particles is introduced in section 3. The application of this method for analyzing the particle shape and size distributions is described in section 4. Finally, a conclusion and perspectives are drawn in section 5 .

\section{EXPERIMENTAL SETUP}

The experimental setup of the batch crystallization process of Ammonium Oxalate crystals is conducted in pure water. $^{11}$ Figure 1(a) illustrates the materials and the imaging system of the experiment. The reactor is a 2L, double-jacketed, glass vessel provided by a condenser. The mixer is a 3 blades, profiled, propeller, and baffles (Mixell TT) driven by a motor with a speed of $300 \mathrm{rpm}$ which is sufficient to obtain a homogeneous suspension. The temperature of the crystallizer is controlled by a heating/cooling bath provided with an external probe of temperature $P t 100 \Omega$ in a feedback control way.

The In situ imaging system consists of a probe (EZProbe sensor) ${ }^{8,12}$ equipped with a CCD monochrome camera with high resolution up to $4 \mu \mathrm{m}^{2}$ per square pixel, and $640 \times 480$ pixels per image. The video images are acquired by a frame grabber with a rate of $25 \mathrm{fps}$. Images of particles are formed using a transmitted light conducted within the probe by optical fibers from the light source. Figure 1(b) illustrates an in situ image example of Ammonium Oxalate crystals obtained during this experiment.

\section{IMAGE SEGMENTATION METHOD}

A method based on the geometric properties of the particle shapes has been developed to detect the overlapped rectangular and regular/irregular prismatic crystals by the assumption that each particle can be constructed from 


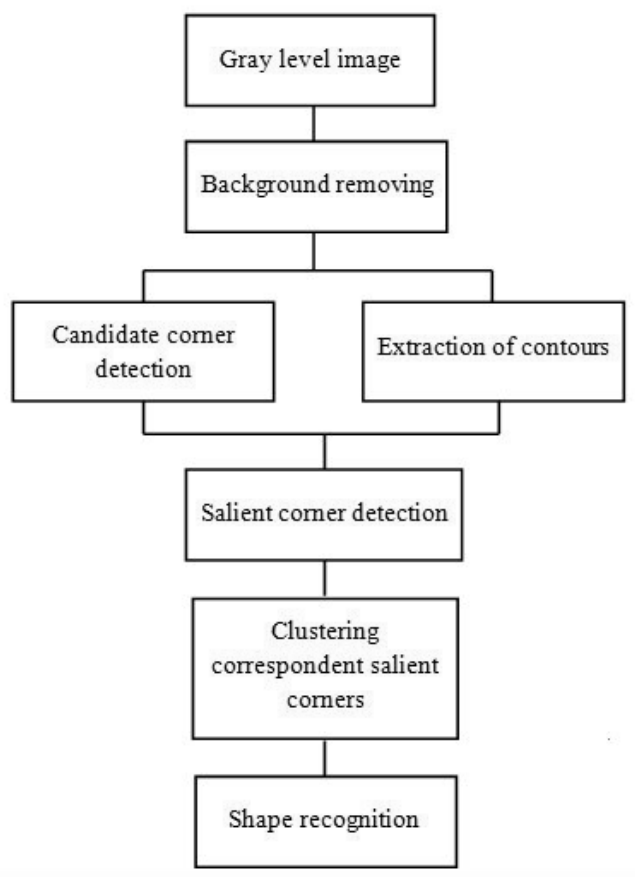

Figure 2. The diagram of the proposed method

grouping three of their correspondent salient corners that belong to the same particle. A computer simulation process has been presented in order to validate the method, and then experiments have been implemented on the real images.

The method (see Fig. 2) is divided into two main parts involving the detection of salient corners from the gray scale image, then recognizing the shape by clustering the correspondent salient corners that satisfy certain geometric conditions.

\subsection{Salient Corner Detection}

Many approaches have been developed for the corner detection because of its importance in computer vision, and pattern recognition applications. Some methods ${ }^{13-15}$ extract the corners directly from the gray level image. However, they are not sufficient for the present work since the orientation of salient corners is also required (see Eq. 1). Other methods ${ }^{16-18}$ extract the boundaries of the objects and then detect the corners from the planar curves or arc segments. Although, the performance of some of these methods depends on the robustness of extracting the arc segments from the gray level image. ${ }^{17}$

A salient corner $C_{i}$ is defined, in this work, by the intersection of its two associated edges in the image spatial support $D$ as follows:

$$
C_{i}=\left\{\left(x, y, \overrightarrow{u_{1}}, \overrightarrow{u_{2}}\right)_{i}:(x, y) \in D,\left\|\overrightarrow{u_{1}}\right\|^{2}=1,\left\|\overrightarrow{u_{2}}\right\|^{2}=1\right\}
$$

The salient corner detection method is based on extracting the candidate corners from the gray level image, and then on analyzing these corners in the edge image (see Fig. 2) to finally identify the salient corners. Firstly, a preprocessing on the gray level image is needed to increase the contrast and to remove the illumination heterogeneity of the background (see Fig. 3(c)), then the candidate corners are detected from the restored image by Rosten method $^{15}$ as illustrated in Figure 3(d). Secondly, the binary edge image is obtained using a multi-scale edge detection, ${ }^{5}$ because it shows efficiency in extracting the boundaries of the semi-transparent overlapped particles whereas the strength of the edge is affected by the overlap (see Fig. 3(e)). Canny detector ${ }^{19}$ is used to get the edges from different scales, then a set of morphological operations ${ }^{20}$ and edge cleaning are done to extract the final contour of the overlapped particles (see Fig. 3(f)). Finally, the direction of the salient corners is obtained 


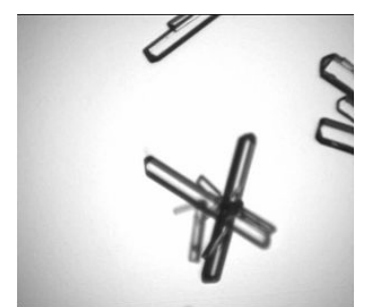

(a)

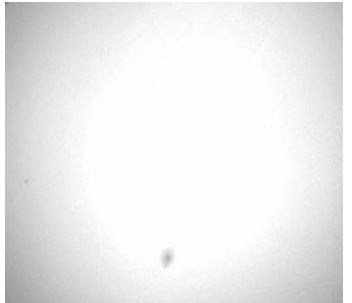

(b)

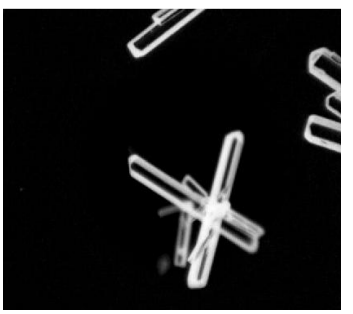

(c)

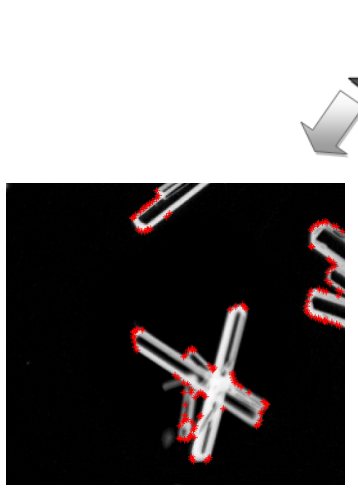

(d)

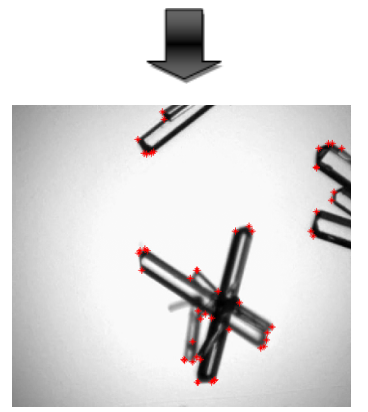

(f)

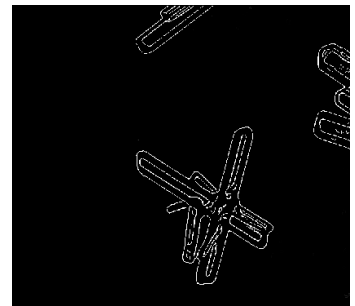

(e)

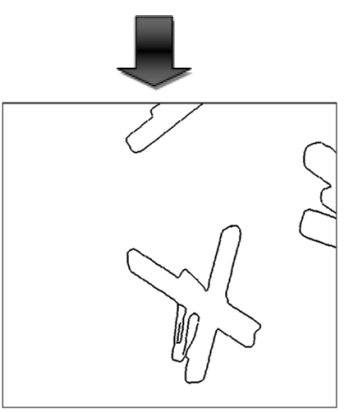

(g)

Figure 3. Example of the salient corner detection applied on a real image of Ammonium Oxalate crystals. (a) Original gray level image. (b) Background image. (c) Removing the background from image (a). (d) Candidate corners image. (e) Multi-scale edge detection. (f) Edge image after contour completion and edge cleaning steps. (g) Salient corners image. 


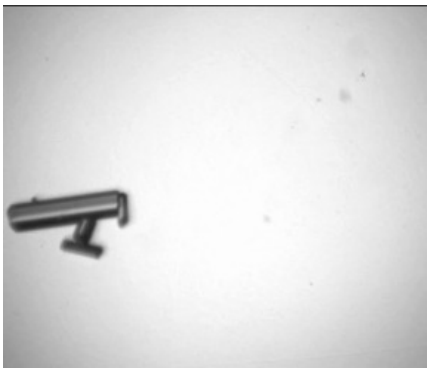

(a)

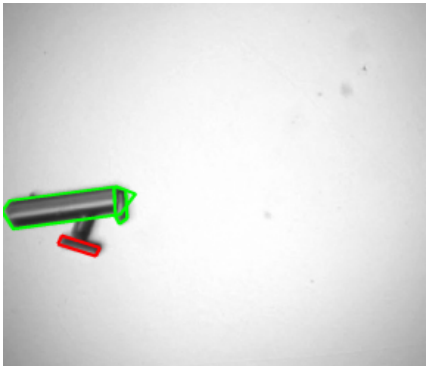

(d)

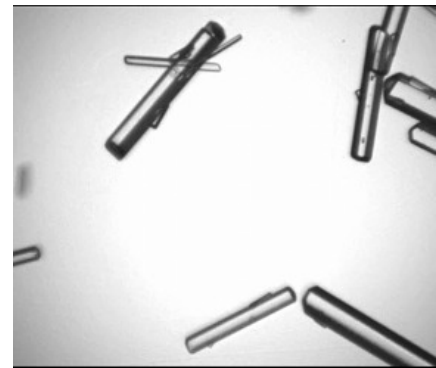

(b)

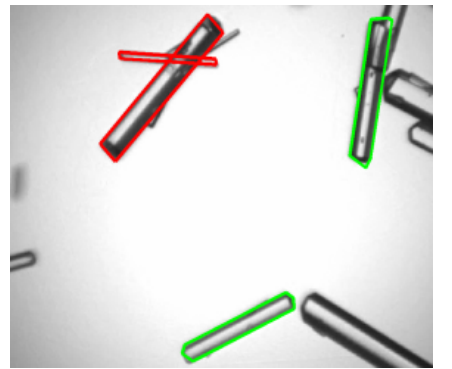

(e)

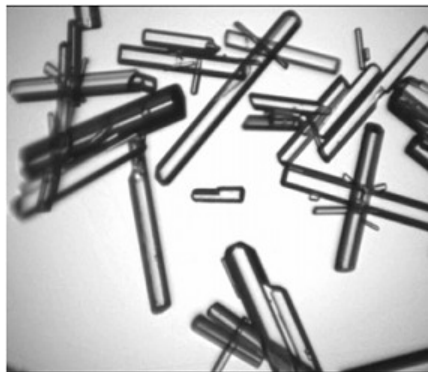

(c)

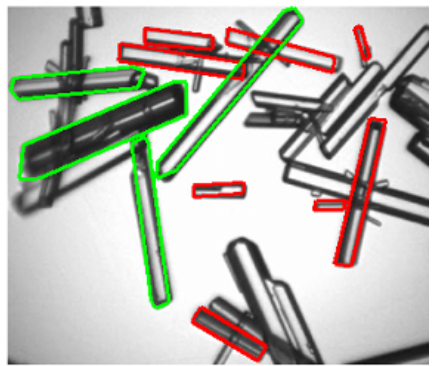

(f)

Figure 4. Examples of real images of overlapped Ammonium Oxalate crystals in low, intermediate and high solid concentrations respectively. (a)-(c). Original images. (d)-(f). Recognized particles

from the directional correlation function, denoted E, which is defined in Equation 2:

$$
\forall \theta \in\left[0,5^{\circ}, 10^{\circ}, \cdots, 360^{\circ}\left[: E(\theta)=\sum_{x=1}^{M} \sum_{y=1}^{N} W_{C_{i}}(x, y) \times T_{\theta}(x, y)\right.\right.
$$

where $W_{C_{i}}$ is the binary edge image restricted to a window of size $M \times N$ pixels centered at corner $C_{i}$, and $T_{\theta}$ is a line template oriented at $\theta^{\circ}$.

The correlation function of the salient corners has two major peaks that refer to its associated edges. Other corners such as junctions will have more than two dominant peaks, while the correlation values at the isolated points will be near zero with no significative peaks. Consequently, all corners which have less or more than two dominant peaks are removed. So an image of salient corners is obtained as illustrated in Fig. $3(\mathrm{~g})$

\subsection{Shape Recognition from clustering method}

Following the salient corner detection, a clustering technique is performed for extracting the final shape of the particles. The procedure depends on searching three correspondent corners that satisfy geometric conditions and thus belong to the same particle.

The clustering technique is developed for recognizing rectangular and regular/irregular prismatic overlapped particles, whereas the general shape of the Ammonium Oxalate crystals is shown to be like rectangular or prismatic shape with faces of different growth rate under the experimental conditions. ${ }^{21}$

The method is evaluated on 150 images acquired in low, intermediate and solids concentrations, successively (see Fig. 4) and a quantitative comparison with the visual recognition by a human expert is illustrated in Table 1. The results show that the method is efficient in detecting the particles in low, intermediate, and even high solids concentrations. Indeed, more than $75 \%$ of the particles could be sightly recognized, which is sufficient for monitoring the size distributions. 
Table 1 Quantitative comparison between automatic and visual recognition for 150 images of overlapped Ammonium Oxalate particles:

\begin{tabular}{l|c|c|c}
\hline \hline Particles (numbers) & Low overlap & Intermediate overlap & High overlap \\
\hline Manually recognized $\left(N_{V}\right)$ & 130 & 149 & 374 \\
\hline Automatically recognized $\left(N_{A}\right)$ & 125 & 137 & 327 \\
\hline Right $N_{R}$ & 125 & 122 & 281 \\
\hline Missed $N_{M}=N_{V}-N_{A}$ & 5 & 12 & 47 \\
\hline False $N_{F}=N_{A}-N_{R}$ & 0 & 15 & 46 \\
\hline $\begin{array}{l}\text { Right to automatic recognition ratio } \\
\text { in percentage }\left(N_{R} / N_{A}\right) \%\end{array}$ & $100 \%$ & $89.1 \%$ & $85.9 \%$ \\
\hline $\begin{array}{l}\text { Missed to visual recognition ratio } \\
\text { in percentage }\left(N_{M} / N_{V}\right) \%\end{array}$ & $3.9 \%$ & $8.1 \%$ & $12.6 \%$ \\
\hline $\begin{array}{l}\text { False to automatic recognition ratio } \\
\text { in percentage }\left(N_{F} / N_{A}\right) \%\end{array}$ & $0 \%$ & $10.9 \%$ & $14.1 \%$ \\
\hline $\begin{array}{l}\text { Right to visual recognition ratio } \\
\text { in percentage }\left(N_{R} / N_{V}\right) \%\end{array}$ & $96.2 \%$ & $81.9 \%$ & $75.2 \%$ \\
\hline
\end{tabular}

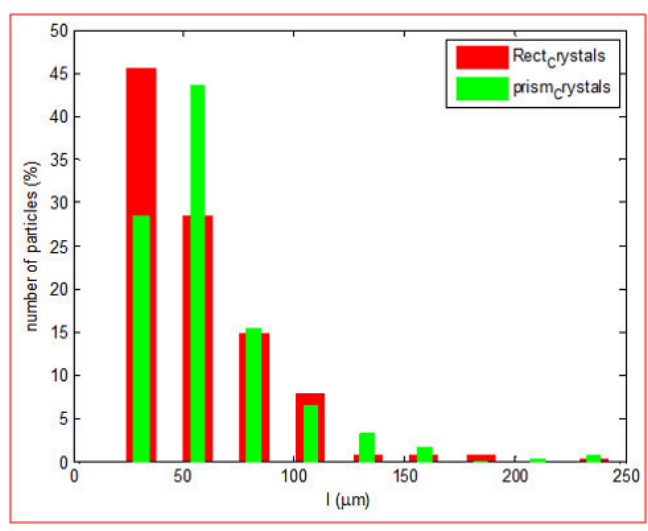

(a)

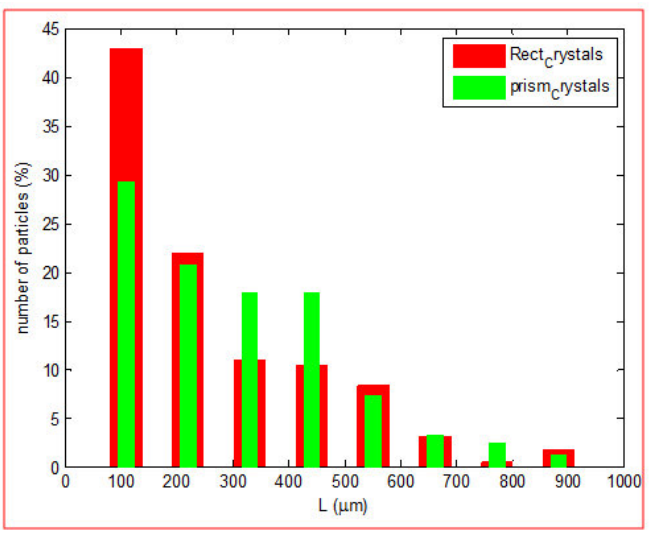

(b)

Figure 5. Particle length and width distributions. (a) Particle width distribution of prismatic and rectangular crystals. (b). Particle length distribution of prismatic and rectangular crystals.

\section{PARTICLE SIZE DISTRIBUTIONS}

Following the segmentation process, the particle size distributions are illustrated for 3 sets of video sequence images, each set contains 50 images, which are acquired in low, intermediate and high solids concentrations. The length and width of each detected crystal is calculated for all image sets and the size distributions are evaluated ${ }^{22}$ for illustrating the frequency of each length and width parameters of the crystals during the experiment (see Fig. 5). The results show that the particles have a tendency to exhibit a prismatic shape in high agglomeration, whereas the small particles exhibit a rectangular shape. Small particles refer to the nucleation process and the beginning of the experiment. Thus, the Ammonium Oxalate crystals have a rectangular shape in low concentrations, then the faces grow to take a prismatic shape in high concentrations. This analysis is important for characterizing the flow properties, dissolution rate, agglomeration tendencies, mixing and demixing properties, filterability, etc. ${ }^{23}$

A quantitative comparison between automatic and manual sizing is performed (see Fig. 6) using the cumulative distribution function (CDF), which is independent of the bins width or number contrary to the particle size distribution function. The normalized error is calculated for both length and width cumulative distributions:

$$
\operatorname{Err}=\sum \frac{\mid \text { Cumh }_{M}-\text { Cumh }_{A} \mid}{\text { Cumh }_{M}}
$$




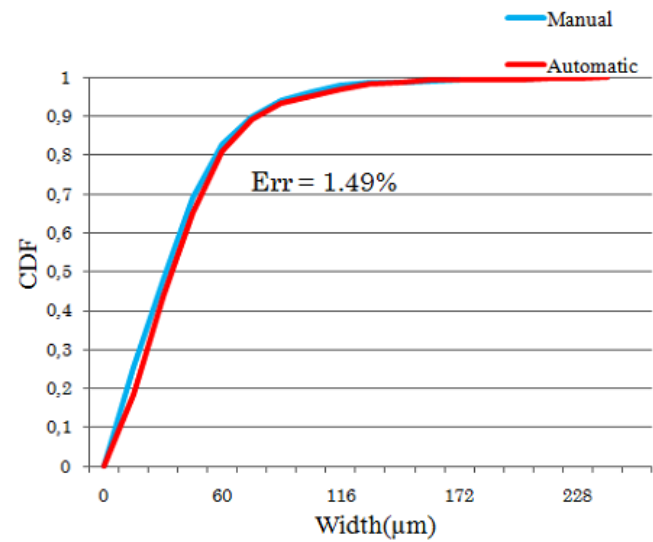

(a)

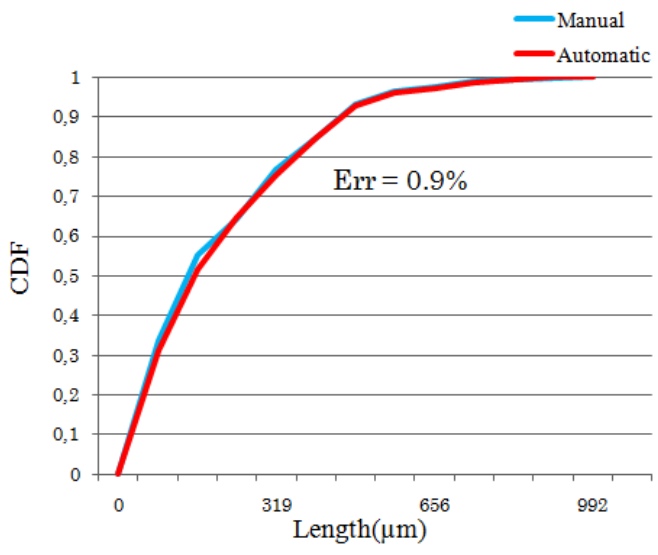

(b)

Figure 6. Comparison of cumulative distribution functions (CDF) of particles length and width for 150 in-situ images. (a) Comparison of particles width distributions. (b). Comparison of particles length distributions.

where $C u m h_{M}, C_{u m h}$ are the cumulative distributions of manual and automatic sizing, respectively.

The results are satisfying and show that the proposed automatic recognition method could be used for analyzing the particle size distributions of the overlapped particles.

\section{CONCLUSION AND PERSPECTIVES}

A recognition method of overlapped particles based on salient corner detection and geometric grouping has been described and applied. The method is proposed to recognize rectangular, regular and irregular prismatic shapes. Then, the particle size distributions are measured on a set of video sequence images in different solid concentrations. A quantitative comparison between the present method and the visual recognition by a human expert is performed. The results show that the method can recognize generally more than $96 \%, 81 \%$ and $75 \%$ of the particles recognized by the human vision in low, intermediate and high solids concentrations, respectively. The cumulative distribution functions of particles width and length are calculated for both manual and automatic sizing. The maximum normalized difference between the cumulative distribution functions was $1.5 \%$. The method can be generalized to detect parallelograms or other convex quadrilateral forms. It could be modified for recognizing other geometric polygons by clustering their correspondent salient corners according to the geometric properties of the desired shape. In the difficult cases of overlap, when the image contains a large number of semitransparent overlapped particles, it becomes difficult to recognize accurately the particles, which might decrease the recognition percentage. So, our future work is to ameliorate the method by estimating the shape using the likelihood function and the clustering propability of two or three salient corners that belong to the same polygonal shape.

\section{ACKNOWLEDGMENTS}

Financial support from French Research Agency ANR is partly provided for the project IPAPI (Improving the Properties of Active Pharmaceutical Ingredients), ref. 07-BLAN-0183.

\section{REFERENCES}

1. J. C. D. Anda, X. Wang, X. Lai, and K. Roberts, "Classifying organic crystals via in-process image analysis and the use of monitoring charts to follow polymorphic and morphological changes," Journal of Process Control 15(7), pp. 785-797, 2005.

2. P. Larsen, J. Rawlings, and N. Ferrier, "An algorithm for analyzing noisy, in situ images of high-aspect-ratio crystals to monitor particle size distribution," Chemical Engineering Science 61(16), pp. 5236-5248, 2006. 
3. J. Burns, A. Hanson, and E. Riseman, "Extracting straight lines," IEEE Transactions on Pattern Analysis and Machine Intelligence 8, pp. 425-455, 1986.

4. P. Larsen, J. Rawlings, and N. Ferrier, "Model-based object recognition to measure crystal size and shape distributions from in situ video images," Chemical Engineering Science 62(5), pp. 1430-1441, 2007.

5. J. C. D. Anda, X. Wang, and K. Roberts, "Multi-scale segmentation image analysis for the in-process monitoring of particle shape with batch crystallisers," Chemical Engineering Science 60(4), pp. 1053-1065, 2005.

6. J. Wan, C. Y. Ma, and X. Z. Wang, "A method for analyzing on-line video images of crystallization at high-solid concentrations," Particuology 6(1), pp. 9-15, 2008.

7. S. Beucher, "The watershed transformation applied to image segmentation," in Scanning Microscopy International, Proceedings of the 10th Pfefferkorn conference on signal and image processing in microscopy and microanalysis 6, pp. 299-314, 1991.

8. B. Presles, J. Debayle, G. Fevotte, and J. C. Pinoli, "Novel image analysis method for in situ monitoring the particle size distribution of batch crystallization processes," Journal of Electronic Imaging 19, pp. 1-7, 2010 .

9. O. S. Ahmad, "Caractérisation géométrique et morphologique par analyse d'image $2 \mathrm{~d}$ de distributions de particules anisotropes et/ou agrégées," Master's thesis, École National Supérieure des Mines, Saint-Etienne, France, 2010.

10. O. S. Ahmad, J. Debayle, and J. C. Pinoli, "A geometric-based method for recognizing overlapped polygonalshaped and semi-transparant particles in gray level images." Submitted paper.

11. N. Gherras and G. Févotte, "Observations sur les nucléations multiples en présence d'impuretés et conséquences pratiques," in Société Française de Génie des Procédés, SFGP,Paris. France 6, pp. 1-8, 2010.

12. B. Presles, J. Debayle, A. Rivoire, G. Févotte, and J. C. Pinoli, "Monitoring the particle size distribution using image analysis during batch crystallization processes," in 9th IEEE/SPIE International Conference on Quality Control by Artificial Vision (QCAV), Wels, Austria, 2009.

13. C. Harris and M. Stephens, "A combined corner and edge detection," in Proceedings of The Fourth Alvey Vision Conference, Manchester, UK, pp. 147-151, 1988.

14. S. M. Smith and J. M. Brady, "A new approach to low level image processing," International Journal of Computer Vision 23, pp. 45-78, 1995.

15. E. Rosten and T. Drummond, "Fusing points and lines for high performance tracking," in Proceedings of the Tenth IEEE International Conference on Computer Vision - Volume 2, pp. 1508-1515, IEEE Computer Society, 2005.

16. X. Zhang, H. Wang, M. Hong, L. Xu, D. Yang, and B. C. Lovell, "Robust image corner detection based on scale evolution difference of planar curves," Pattern Recognition Letters 30(4), pp. 449-455, 2009.

17. F. Shen and H. Wang, "Corner detection based on modified hough transform," Pattern Recognition Letters 23(8), pp. 1039-1049, 2002.

18. C. H. Teh and R. T. Chin, "On the detection of dominant points on digital curves," IEEE Transactions on Pattern Analysis and Machine Intellegence 11(8), pp. 859-872, 1989.

19. J. Canny, "A computational approach to edge detection," IEEE Transactions on Pattern Analysis and Machine Intelligence 8, pp. 679-698, 1986.

20. P. Soille, Morphological image analysis: principles and applications., Second Edition. Springer-Verlag Berlin Heidelberg, 2003.

21. M. Jakubczyk and R. Misztal, "Morphology and kinetic of crystal growth," Visnyk of Lviv University. Series Physical. Ukraine 40, pp. 180-184, 2007.

22. D. W. SCOTT, "On optimal and data-based histograms," Biometrika 66(3), pp. 605-610, 1979.

23. T. Allen, Powder sampling and particle size determination, Elsevier, Amsterdam, 2003. 